Behavior and Social Issues, 16, 190-196 (2007). (C) Stephen E. Wong. Readers of this article may copy it without the copyright owner's permission, if the author and publisher are acknowledged in the copy and the copy is used for educational, not-for-profit purposes.

\title{
SCIENTIFIC Discovery, Social ChANGe, AND INDIVIDUAL BEHAVIOR CHANGE
}

\author{
Stephen E. Wong ${ }^{1}$ \\ Florida International University
}

\begin{abstract}
Scientific discoveries and technological advances are achieved through the expenditure of human and material resources. Clinical research and program development in mental health services are no exceptions. In the present rejoinder to Dr. Wakefield's second critique, this point is briefly discussed as well as fallacies in his claim that across-setting generalization was the main reason why behavioral programs have not been more widely utilized in the treatment of psychosis.

KEYWORDS: behavior analysis of psychosis, schizophrenia, generalization of trained skills, mental health political economy
\end{abstract}

Scientific and technological breakthroughs often require sizable investments of human labor and material resources. For a notable example, in 1961 President John F. Kennedy devoted the work of thousands of scientists, engineers, and other skilled technicians and an estimated \$25 billion to the Apollo Project with the goal of putting a man on the moon (Koman, 1994). This stunning feat had never before been achieved by any nation on earth and it has not been repeated since. Could the project have been successfully completed with considerably fewer workers and at one-half the cost? Recalling the tragic deaths of three astronauts in the launch pad fire of the Apollo 1 and the nearly disastrous events that scuttled the Apollo 13 mission, probably not.

Once scientific discoveries are made, a modern society's usage of these findings depends on their broad acceptance and changes in the individual behavior of many members of the population. Consider how the transmission of bacteria and disease has been prevented by encouraging people to wash their hands, how scurvy has been virtually eliminated by getting everyone to eat fresh fruits and vegetables containing vitamin $\mathrm{C}$, and how tooth decay has been reduced by convincing people to brush their teeth daily with fluoride toothpaste. The success of these public health programs depended not only on the original scientific discoveries but also on the widespread adoption of practices that applied the new knowledge.

It was from this perspective that I wrote the article, "Behavior Analysis of Psychotic Disorders: Scientific Dead End or Casualty of the Mental Health Political Economy?" My review of the literature suggested that after a brief trial in the late $60 \mathrm{~s}$ and early $70 \mathrm{~s}$ by a few hundred psychologists (at most) and a handful of psychiatrists, behavioral

${ }^{1}$ Correspondence concerning this article should be sent to Stephen E. Wong, School of Social Work, Florida International University, wongse@,fiu.edu. 


\section{SCIENTIFIC Discovery, SOCIAL CHANGe, AND INDIVIDUAL BeHAVIOR CHANGE}

treatments for psychoses and severe mental disorders were largely abandoned in favor of psychotropic drugs. This abandonment did not follow a string of failures to replicate or other negative findings, although research of the time did identify certain limitations -- as might be expected in a nascent treatment for a vexing problem. Unlike for dominant biomedical approaches, the work of tens of thousands of mental health professionals and hundreds of billions of dollars were not dedicated for over half a century to exploring, developing, and applying psychosocial and environmental interventions for severe mental disorders. My paper pointed out something rather simple and obvious - compared to the resources devoted to the biomedical model, behavioral approaches had not been given a fair test. I then gave an overview of ways in which supporters of biomedical interventions have secured and maintained control over public opinion, governmental policy, thirdparty funding, and mental health practices.

Now Professor Wakefield returns with another lengthy paper reiterating and defending many points of his first review. After dubbing his paper with the inflammatory title, "Is Behaviorism Becoming a Pseudoscience?...," he complains about the "vigorous, quite harsh" rebuttals by Drs. Wyatt, Midkiff, and myself, and the ensuing "...heated rhetoric." As he did in his first review, Dr. Wakefield circumvents the main points of my article and finds fault in peripheral issues that he claims disprove my central thesis. In their eloquent and incisive rebuttal, Drs. Wyatt and Midkiff (this issue) refute point-bypoint most of the issues in Dr. Wakefield's second critique. Rather than attempting a similar comprehensive response, I will merely focus on a few key points of Dr. Wakefield's critique and then return to the larger topic that was the subject of my paper.

\section{GENERALIZATION OF TOKEN ECONOMY EFFECTS}

One of Dr. Wakefield's main criticisms revolves around the limited generalized effects that have been reported for token economy programs. In the abstract of his second review he writes: "I (Wakefield, 2006) argued that the treatment's fate was due to its own limitations, particularly the failure of effects to generalize adequately to natural environments given deinstitutionalization." And, a few lines later: "I conclude that we all agree that such treatments were not shown to adequately generalize, providing a scientific reason for the treatment's fate." (Wakefield, this issue, p. 170).

Dr. Wakefield dismisses my reference to basic and applied behavioral research on generalization as a "non sequitur" to his criticism of the limited generalization for token economies (Wakefield, this issue, p. 177). He asserts that research on the "concept and process of generalization" is "...irrelevant to the present dispute" concerning treatment programs for schizophrenia. Earlier he writes, "In my view, each disorder must be considered individually regarding the issues in dispute" (Wakefield, this issue, p. 172), thus implying that the discussion of generalization must be broken down according to clients' specific psychiatric diagnosis.

I contend that behavioral research on generalization was germane to Dr. Wakefield's criticism and logically connected to the discussion. Generalization is a common and well understood behavioral phenomena and an informed discussion of this topic cannot be 
arbitrarily restricted to carry-over effects for a specific therapy technique used with a particular group of clients. The treatment approach for severe mental disorders reviewed in my article is based on a science of behavior that searched for and uncovered natural laws with broad generality. Principles of behavior such as reinforcement, extinction, and generalization have been replicated with pigeons, rats, dogs, cats, reptiles, fish, certain invertebrates (cephalopods), sea lions, whales, and all sorts of primates, including humans with a wide spectrum of behavioral problems. These scientific principles have been shown to operate in the wild, and in zoos, laboratories, hospitals, clinics, schools, and open community settings around the world. Why would these highly robust principles not also govern the generalization of desired behavior change in persons with severe mental disorders, if these principles were ever directed to this purpose? In contrast, the diagnosis of schizophrenia is not a very reliable construct nor is it consistently correlated with any physical anomaly that would support the notion of it being a distinct biological condition. Why should we ignore well-established behavioral principles in favor of unreliable psychiatric diagnoses, other than out of deference to psychiatric authority?

The references I made to research in promoting generalization of trained skills in persons with autism and other developmental disorders also showed that behavioral researchers have made substantial progress in producing this form of behavior change when they had stable research programs and worked on this issue over a sustained period of time. It is worth noting that the Wong et al. (1993) study, one of the few to have demonstrated limited but reliable generalization of trained skills in chronic schizophrenic patients, was conducted without external funding and mostly with students and volunteers assisting on a dissertation project. Due to lack of internal and external institutional support, the research group working on this study disbanded when the project was completed. Regrettably, we were only able to do a one-shot study on the generalization of newly acquired social skills. Based on what was accomplished with these minimal resources, it is reasonable to predict that if our research group had been given more support (e.g., one-one thousandth of the $\$ 800$ million that is supposedly spent on the development of each new drug brought to market) we likely would have completed additional studies, each more refined, more advanced, and producing better generalization than that reported by Wong et al. (1993).

In both in the current critique and the previous one, Dr. Wakefield characterizes generalization as an insurmountable problem that provides the logical justification for dispensing with behavioral programs. To support his argument Dr. Wakefield quotes several researchers who commented on the limited or inadequate generalization obtained with previous behavioral programs (Wakefield, 2007, p. 175-176). These quotations, however, are often taken out of context and misrepresent the authors' message. For example, a few pages after Dr. Wakefield's quote from Kazdin and Bootzin, the authors provided a section nearly three pages long entitled, "Procedures to Increase Generalization" describing techniques that have been successfully employed to promote generalization across settings (Kazdin \& Bootzin, 1972, pp. 361-364). The quote from Glynn et al. (2002) is taken from a study of social and independent skills training whose 


\section{SCIENTIFIC Discovery, SOCIAL CHANGe, AND INDIVIDUAL BeHAVIOR CHANGE}

main innovation is manual-based in vivo training designed to promote skills generalization. This study hardly represents capitulation to the obstacle of extra-therapy setting generalization. Similarly, the article by Kopelowicz, Liberman, and Zarate contained numerous guidelines for increasing generalized effects of social skills training in sections entitled, "Community Supporters" and "Enhancing Generalization" (Kopelowicz, et al., 2006, S16, S20-21). Contrary to the dire picture painted by Dr. Wakefield, the above authors merely identified the promotion of generalization as an area for future research and program development. They did not in any way indicate that generalization was a clinical barrier that should cause researchers and clinicians to drop behavioral interventions in favor of drug treatment. Portraying this as the authors' position is a gross misrepresentation and a disservice to interested readers.

One of the recommendations for promoting generalization made by several of the above authors involves restructuring clients' home and community environments to duplicate reinforcement contingencies created in therapeutic settings. Kazdin and Bootzin wrote, "...it is our guess that the most fruitful techniques (for increasing generalization) will be ones that emphasize programming the natural environment." (Kazdin \& Bootzin, 1972, p. 364). This advice was later echoed in Kazdin's book, The Token Economy (Kazdin, 1977, pp. 180-183), which covered the topic in greater depth. Kopelowicz and his associates also recommended a similar approach to enhancing generalization through teaching case managers and family members to encourage and reward clients' use of trained skills in the community and at home (Kopelowicz, et al., 2006, p. 5). Recruiting community mental health professionals and family members to apply positive reinforcement, successive approximation, extinction, and other behavioral techniques in clients' natural environment is a crucial step at which procedures developed and evaluated in research settings are transferred to natural environments. Like the public health programs mentioned at the start of this article, this is the point at which research findings are implemented by large numbers of people in their homes and communities. Dr. Wakefield ignored these recommendations of authors that he cited. Instead, he chose to write a second, slightly less disparaging review of behavioral programs, but one that still discourages the wider application of these empirically-validated procedures with severe mental disorders.

\section{ETIOLOGY OF SCHIZOPHRENIA}

This is another tangential topic that Dr. Wakefield erected as a target for his criticism of my article. It should be noted that this topic does not appear as a heading nor is it discussed at any length in my original paper (Wong, 2006a). I confess that Dr. Wakefield successfully baited me into mentioning the etiology of schizophrenia in my response to the commentaries (Wong, 2006b). However, I am now willing to say that to my knowledge there is no well-articulated behavioral theory of the etiology of schizophrenia. As my article pointed out, for the last 30 years there has been minimal behavior analysis research on schizophrenia. Behavioral theories about how this disorder 
WONG

develops would require intensive and lengthy longitudinal studies that have not been funded or supported in other ways, and hence do not exist.

When I cited Allyon, Haughton, \& Hughes (1965), who demonstrated that reinforcement contingencies could both produce and eliminate psychotic behavior, I was pointing out how environmental conditions might contribute to the emergence of psychoses. The study by Allyon et al. (1965) involved only one subject, which is obviously insufficient upon which to build a theory of the origin of schizophrenia. However, while claiming to "...not scoff at the idea that environmental conditions can influence the development of schizophrenia" (Wakefield, this issue, p. 186), Dr. Wakefield was quick to belittle this striking demonstration of contingency-produced psychotic symptoms. But, regardless of our differing opinions about the etiology of this disorder, this was not a focus of my article and it is not an issue I wish to further dispute with Dr. Wakefield.

\section{Science as a Rational, Progressive Process}

Dr. Wakefield characterizes the biomedical approach to mental disorders as being the epitome of good science: "Biological research has the virtue of being a progressive paradigm that offers novel hypotheses, acknowledges evidential weaknesses and addresses them with further studies, and gives up hypotheses when disconfirmed" (Wakefield, this issue, p. 174). This rosy view of biomedical research turns a blind eye to numerous discrepancies in empirical data and the pharmaceutical industry's pervasive and long- standing pattern of manipulating scientific activity recounted by Drs. Wyatt and Midkiff (2006) and myself. Professor Wakefield also maintains that behavioral treatments were displaced solely because of the "scientific, non-political reason" of poor generalization (Wakefield, this issue, p. 176), a misreading of the literature and an idealized view of science.

Science is a social enterprise involving groups of individuals who work with different conceptual models and research methodologies, who compete for recognition and resources, and who advocate for the broader acceptance of their own approach. To characterize science as a process detached from people, their personal biases, and their vested interests is a disembodied abstraction. Science, particularly science involving mental health services, is embedded in other larger social processes and institutional transformations such as:

- University budget shortages raising the priority of funded research

- Professional education and interdisciplinary struggles for practice jurisdictions

- Service organizations and industries vying for insurance and private payment

- Capital investment and competition for market share

- State and federal law and policy pertaining to mental health services

- Corporate influence of government through lobbying and campaign contributions, and

- Corporate influence of public opinion through commercial mass media 


\section{SCIENTIFIC Discovery, Social CHANGE, AND INDIVIDUAL BEHAVIOR CHANGE}

Academic psychologists and social workers also operate within this complex political-economic web and have little leeway in the kinds of interventions they can study and develop.

Just as the walk on the moon and the U.S. space program was not initiated or decided upon by astrophysicists and aeronautical engineers, the treatment of persons with severe mental disorders is not primarily determined by psychologists, social workers, or even psychiatrists. Although mental health professionals are able to make minor adjustments within their approved span of practice and have some input into the kind of work they do, the perception of professional self-determination is mostly illusionary. The majority of mental health professionals, including leading academics and researchers, are happy to work when and where they can find it. And, just as the U.S. space program was not determined solely by Presidential order but also by a confluence of historicalgeopolitical events (i.e., the nuclear Cold War, the Soviet Union's early lead in the space race and successful launching of Sputnik, and U.S. desire to regain technological superiority and global prestige) (Koman, 1994), the shift away from behavioral toward pharmacological treatments was not due to poor outcomes of the former and superior outcomes of the latter, and certainly not due the narrow issue of across-setting generalization. This shift was more likely due to the growing wealth and power of commercial sectors within our society, including the pharmaceutical industry; the systematic diversion of public and private funds towards profit-generating, short-term solutions to human concerns; and the corresponding relative decline in expenditures for preventive, educative, rehabilitative, behavioral, and other socially constructive strategies for dealing with human problems. These overarching conditions are rarely mentioned in discussions of mental health services and they will be very difficult to change. Nevertheless, the first step in addressing any significant problem is recognizing and analyzing its actual causes.

\section{REFERENCES}

Glynn, S. M., Marder, S. R., Liberman, R. P., Blair, K., Wirshing, W. C., Wirshing, D. A., Ross, D., \& Mintz, J. (2002). Supplementing clinic-based skills training with manual-based community support sessions: Effects on social adjustment of patients with schizophrenia. American Journal of Psychiatry,159(5), 829-837. http://dx.doi.org/10.1176/appi.ajp.159.5.829

Kazdin, A. E. (1977). The token economy: A review and evaluation. New York: Plenum Press.

Kazdin, A. E., \& Bootzin, R. R. (1972). The token economy: An evaluative review. Journal of Applied Behavior Analysis, 5, 343-372. http://dx.doi.org/10.1901/jaba.1972.5-343

Koman, R. G. (1994). Man on the moon: The U. S. space program as a cold war maneuver. OAH Magazine of History, 8(Winter). Retrieved August 5, 2007, from http://www.oah.org/pubs/magazine/coldwar/koman.html

Kopelowicz, A., Liberman, R. P., \& Zarate, R. (2006). Recent advances in social skills training for schizophrenia. Schizophrenia Bulletin, 32(Supplement 1), S12-S23.

http://dx.doi.org/10.1093/schbul/sbl023

Wakefield, J. C. (2006). Is behaviorism becoming a pseudo-science?: Power versus scientific rationality in the eclipse of token economies by biological psychiatry in the treatment of schizophrenia. Behavior and Social Issues, 15, 202-221. http://dx.doi.org/10.5210/bsi.v15i2.363 


\section{WONG}

Wakefield, J. C. (2007). Is behaviorism becoming a pseudo-science?: Replies to Drs. Wyatt, Midkiff and Wong. Behavior and Social Issues, 16, 170-189.

http://dx.doi.org/10.5210/bsi.v16i2.919

Wong, S. E., Martinez-Diaz, J. A., Massel, H. K., Edelstein, B. A., Wiegand, W., Bowen, L., \& Liberman, R. P. (1993). Conversational skills training with schizophrenic inpatients: A study of generalization across settings and conversants. Behavior Therapy, 24, 285-304. http://dx.doi.org/10.1016/S0005-7894(05)80270-9

Wong, S. E. (2006a). Behavior analysis of psychotic disorders: Scientific dead end or casualty of the mental health political economy? Behavior and Social Issues, 15, 152-177. http://dx.doi.org/10.5210/bsi.v15i2.365

Wong, S. E. (2006b). Response to the commentaries. Behavior and Social Issues, 15, 232-243. http://dx.doi.org/10.5210/bsi.v15i2.390

Wyatt, W. J., \& Midkiff, D. M. (2006). Biological psychiatry: A practice in search of a science. Behavior and Social Issues, 15, 132-151. http://dx.doi.org/10.5210/bsi.v15i2.372

Wyatt, W. J., \& Midkiff, D. M. (2007). Psychiatry's thirty-five-year, non-empirical reach for biological explanations. Behavior and Social Issues, 16, 197-213.

http://dx.doi.org/10.5210/bsi.v16i2.1874 